\title{
Investigation and Analysis on the Market Demands of Talents Majored in Translation and Master of Interpreting and Translation
}

\author{
Shufen Yang \\ Wuchang Shouyi University, Wuhan Hubei, 430064, China
}

Keywords: Translation Major, Translation Talents, Social Demands, Individual Demands.

\begin{abstract}
To cultivate high-level application-oriented talents, serve the regional development, realize the industrial revitalization and technological progress, it has become the general objective of many universities and colleges to realize transformation development. In order to survive and develop, universities and colleges should stand on the requirements during the development and construction of specialty in transition. Based on the analysis on social and individual demands, this paper investigates the demands of talents majored in translation and translation talents, with the hope of offering orientation and guidance for the development of English major.
\end{abstract}

\section{Industrialization of Translation and Current Situation of Domestic Market}

Under the background of international development, scholars have put forward to cultivate composite(Liu Chunyan, 2012), application-oriented(Gao Xiang, 2002), innovative (Zhuang Zhixiang 2011; Huang Zhending 2013) and international (Wang Xuemei, 2011) talents majored in English. Cai Jigang(2014) et al. point out that, it should start from Chinese demands of foreign language talents and the reality, plan and arrange different levels of talents cultivation in different regions. Different universities and colleges should have their own characteristics and cultivate diversified talents majored in English, further to adapt themselves to the national and social demands.

However, with the development of reform and opening up to the outside word, China has increasingly communicated and cooperated with all other countries in the fields of economy, culture, science and technology, education and politics. The society has greatly increased the expectation of quantity and quality of translation talents. In the meanwhile of gradually more and more translation needs, Chinese translation industry has been majorly confronted by the problem, the service quality and talent management need to be fatherly improved. Meanwhile, insufficient translation team is still the big problem troubling the translation industry. Currently, China has about 6 employed professional translators. It is conservatively estimated that there are 500000 translation practitioners. According to related sampling investigation, the population may achieve 1 million. Even so, the current translation team still cannot meet the huge market demand. Currently, domestic market is mostly insufficient of five trasnlation talents, respectively are technological interpretation, conference interpretation, court interpretation, commerce interpretation, liaison-escort interpretation and documents interpretation. Chinese translation service market is sharply expanding. First of all,there are few English professionals, who are concentrated in few cities and governmental departments with relatively developed economy; secondly, because the English-Chinese translation is relatively easy, the gap of talents is not big, but there are seriously insufficient high-quality talents who are qualified for the Chinese-English job, the gap is estimated to be over $90 \%$. Therefore, students majored in Translation have quite good prospect of employment.

\section{Construction and Development of Translation Major in Chinese Universities and Colleges}

The translation major has already gradually become one emerging major and discipline in Chinese universities and colleges. Since three universities and colleges started to recruit undergraduates majored in translation in 2006, which were approved by The Ministry of Education of the People's Republic of China, a lot of colleges and universities have set up the major of translation, department 
of translation or institute of translation according to social demands and disciplinary development requirement, further to accelerate the development of translation. From 2006 to 2011, dozens of universities and colleges applied to set up the undergraduate major of translation. 57 universities and colleges were approved to try to set up the undergraduate major of translation during 6 years. In 2012, "translation" was no longer the "experimental major beyond the catalogue", which entered the basic catalogue and became the official undergraduate major of universities and colleges. In the next year, there were 49 universities and colleges approved by The Ministry of Education(Ping Hong, 2014).

In China mainland, eight groups of universities and colleges have already set up the undergraduate major of translation, 106 in all. 159 universities and colleges have set up MTI (Chai Mingying, 2013). The objective of MTI is to cultivate high-level, application-oriented and professional translation and interpretation talents with all-round development of morality, intelligence and physique, who can adapt themselves to economic globalization and the demands of improving the country's international competitiveness, and also construction demands of national economic and cultural society(Zhong Weihe, 2010).

Establishment of the translation major is the requirement for the development of times. To set up independent and complete translation discipline stations, it is the requirement for China's in-depth development of reform and opening up and integration with the process of globalization, for China to consistently accelerated the international communication and increase the communication, and also the demand to cultivate a lot of high-quality translation talents. As the major medias of foreign communication, it has already become the social demands and micro-perspective individual demands to cultivate high-quality translation talents with strong abilities(Zhuang Zhixiang).

\section{Current Situation and Prospect of Translation Industry in Hubei}

Since the reform and opening up, the translation industry of Hubei has obtained the considerable development. Currently, among 96 general institutes of higher education in Hubei, Foreign Languages Department of three colleges and universities have owned doctoral supervisors majored in translation. 9 colleges and universities have set up the MTI major and nearly 10 college and universities' Department of Foreign Languages have set up the Department of Translation. In addition, there are more than 10 institutions in Hubei developing the translation training. There are more than 300 registered translation companies throughout the province, of which, more than 100 are still in operation. Transn and Yuanpei, the two largest translation companies throughout the country, have set up branches or offices in Wuhan. Transn has also set up its main body in Wuhan, namely the global multilingual information processing center.

\section{Questionnaire Investigation at the beginning of 2016--Statistics of Translation Talents Distributed in all Fields}

Establishment of the translation major aims at satisfying the individual demands of learners. Among all kinds of qualification certificates, the translation certificate is really hot. As one occupation and industry, translation has also put forward more and higher requirements for translators. Currently, English majors of all universities and colleges have opened the course of translation. However, translation talents cannot satisfy the market demands. On the fourth National Application-oriented Translation Seminar, Huang Youyi ever pointed out that the society has quite strong demands for application-oriented talents, especially the high-quality application-oriented translation talents. However, the reality is, many students cannot complete the translation tasks involved in the actual work after graduation. There are few students who are engaged in the translation work(Zhu Ailing, 2010). According to statistics, the gap of translation talents in China achieves as high as $90 \%$, of which, it is extremely short of Chinese-English talents. Besides, there are few translation talents conforming to the requirements. Therefore, it has quite strong practical application value to set up the translation major. 
In order to fatherly understand the social demands of translation demands, the author developed a large-scale investigation in January, 2016. The investigation objects mainly included translation practitioners and HR supervisors of employing units. Investigation mainly adopted the way of interview and questionnaire. The interview investigation obtained information by the network, telephone or face-to-face communication. The questionnaire was sent to the translation practitioner or HR supervisor by email. The author got 117 questionnaires of translation practitioners and 106 questionnaires of the employing units.

Conclusions of Investigation and Statistics:

a). Orientations which urgently need talents are enterprise business translation and overseas engineering project translation. The former includes translation of clients' English data, Chinese-English translation of manufacturing equipment, visa of foreign expert, reception of foreign guests, translation of communication and negotiation with foreign clients, order tracking, etc. The latter includes commercial negotiation involved in overseas engineering project, business reception translation, escort interpretation of overseas work, translation of project's contract, etc.

b). Among practitioners, $94 \%$ consider that the translation industry has a quite large social demand, especially the import and export corporations, enterprises and public institutions, travel agencies, translation companies. They have large demands of translation talents, thus the prospect is quite good. Translation practitioners, especially the escort interpreters and simultaneous interpreters, they have quite high wages. However, due to the quite fierce market competition, threshold of translation has become higher and higher. Requirements of translators' professional qualities have also been increased. Except for quite good basic linguistic skills, translators should be equipped with other professional knowledge and high comprehensive qualities. However, currently, it is quite hard to find counter-parting translation talents. The society has a large gap of translation talents.

c). Proportion of translation practitioners engaging in translation activities in different occasions is as follows: it turns out that, most translation practitioners are engaged in meeting translation and conference speaking translation. There are huge demands of escort interpreters and simultaneous interpreters.

\begin{tabular}{cc}
\hline Conference speaking translation & $49 \%$ \\
\hline Translation of speech on large activity & $36 \%$ \\
\hline Translation of commercial negotiation & $43 \%$ \\
\hline Normal meeting translation & $51 \%$ \\
\hline Engineering translation & $42 \%$ \\
\hline Translation of visiting delegation and receiving visiting group & $41 \%$ \\
\hline Others & $9 \%$ \\
\hline
\end{tabular}

d). Posts related to translation and distribution in professional fields, as follows:

Foreign affairs and diplomacy(governmental official document, speeches of leaders, local profile, $\quad 17 \%$ correspondence)

\begin{tabular}{cc}
\hline $\begin{array}{c}\text { Science and Technology(Electronic Machinery, Pharmaceutical Chemicals, Information Technology, Energy } \\
\text { Environmental Protection ) }\end{array}$ & $34 \%$ \\
\hline Economics(Finance, insurance, economy and trade, bidding documents, tourism) & $42 \%$ \\
\hline Culture and education(News, newspaper, ads, magazine, education, broadcast) & $25 \%$ \\
\hline Law(Novel, film, poet, prose, drama) & $17 \%$ \\
\hline Literature (fiction, film, poetry, prose, drama, etc.) & $2 \%$ \\
\hline Practical(All kinds of practical writing, letter, certificate) & $26 \%$ \\
\hline Others & $2 \%$ \\
\hline
\end{tabular}

From the form, it can be seen that, the economics and science\&technology have more translation posts.

e). In the current market, according to the requirements of English-related posts and employment situation of English majors, the recognition degree of certificates is as follows:

\begin{tabular}{cc}
\hline China Accreditation Test for Translators and Interpreters -CATTI & $2 \%$ \\
\hline National Accreditation Examinations for Translators and Interpreters- NAETI & $26 \%$ \\
\hline Certificate of English Translation ( Intermediate and Advanced) & $36 \%$ \\
\hline English Translation Test Of Business Language- ETTBL & $8 \%$ \\
\hline Interpretation Certificate & $45 \%$ \\
\hline European Simultaneous Interpretation Certificate & $17 \%$ \\
\hline
\end{tabular}




\begin{tabular}{cc}
\hline Certificate of English Translation Test of Business Language ( Intermediate and Advanced) & $19 \%$ \\
\hline Test for English Majors Level 4 and 8 & $53 \%$ \\
\hline CET-4 and CET-6 & $8 \%$ \\
\hline Others & $2 \%$ \\
\hline
\end{tabular}

From the investigation results, it can be seen that, the market has high recognition degree of TEM-4 and 8. Besides, certificate of interpretation, Certificate of English Translation ( Intermediate and Advanced) and NAETI have been affirmed by the market. From the perspective of social demands and individual demands of learners, certificates of translation can undoubtedly improve the market competitiveness of English talents.

f). About 95\% surveyed units' management show that, the society has quite large requirements of translation talents, the translation major has quite good development prospect. To varying degrees, there is difficulty of recruiting translation talents. Especially the high-end translation talents are extremely scare. Interpreters and translators are lack of practical abilities and insufficient comprehensive abilities.

\section{Employment Prospect of Master of Interpreting and Translation}

To set up the major of translation, it aims at satisfying the requirements of translation talents at present and in the future, put forward by the reform and opening up and society. Accompanied by the reform and opening up and increasingly frequent international communication, the establishment of MIT is the demand of cultivating a large group of high-quality and high-level translation talents. Due to economic globalization, integration of science and technology, cultural diversity and information networking, it has vigorously promoted international communication and interaction, further to produce huge demands of translation talents and products playing the role of cultural bridge and communication medias. In addition, it has put forward higher requirements of the quality and quantity of translation talents and products.

With more and more international communication and frequent international conferences, it has increased the demand of foreign language talents, comprehensive, innovative and application-oriented foreign language talents, especially all kinds of translation talents, such as advanced interpreter and translator (technical translation, literary translation, literature translation, special subject translation, simultaneous interpretation,inter-translation talents, translation of video-aural-oral materials). No matter national or governmental communication and cooperation in politics, diplomacy, economy, science\&technology, culture and education, or communication among enterprises, schools, social communities and organizations, a large group of translation talents mastering foreign languages and major are urgently needed (Zhuang Zhixiang, 2007).

Master of Interpreting and Translation can undertake the posts of commercial translation, foreign trade negotiation, economy and trade secretary, English editing, English journalist, foreign commercial agency, foreign public relation and foreign tour guide in government agencies, foreign affairs, foreign trade, foreign enterprises, foreign financial organizations, business administration corporations, professional translation organizations, publishing, news, tourism and senior hotels.

By February, 2016, according to the questionnaire results, 94\% consider that the translation industry has huge social demands, especially the import and export corporations, enterprises and public institutions, travel agencies and translation companies, they have huge demands of translation talents and the prospect is quite good. Translation practitioners, especially the escort interpreters and simultaneous interpreters have quite high salaries. However, the market competition is quite fierce and the threshold of translation is getting higher and higher. Requirements of translators' professional qualities are increased as well. Except for quite good basic linguistic skills, translators should possess other professional knowledge and high comprehensive qualities. It is quite difficult for undergraduate talents majored in translation to possess these abilities. Masters and doctors in translation are lacking, which results in difficulty of looking for counterpart translation talents. Therefore, the overall market demand of MIT is quite high, with good employment prospect. 


\section{Acknowledgments}

This research is the phased research result of "the Twelfth Five-year Plan" of Hubei province.Serial No. 2014B317.

\section{References}

[1] Liu Chunyan. Educational Target Framework of Composite Foreign Language Talents, Foreign Language World, 2012(1):10-18.

[2] Gao Xiang, Mu Congjun. Thoughts on Cultivating Composite and Application-oriented Foreign Language Talents, Foreign Language World, 2002(2):10-13.

[3] Zhuang Zhixiang, etc. Thoughts on Cultivating International and Innovative Foreign Talents,Foreign Language World, 2011(6):71-78.

[4] Huang Zhending, Huang Yanchun. Humble Opinion about Cultivating Innovative English Talents, Foreign Language Teaching, 2013(1):61-64.

[5] Wang Xuemei, Xu Lu. Explorations of Connotations and Cultivating Modes of International Composite Talents, Foreign Language and Foreign Language Teaching, 2011(1):9-12.

[6] Cai Jigang. From General English to Academic English--Returning to English Teaching Standard of Universities and Colleges, Foreign Language and Foreign Language Teaching, 2014(1):9-14.

[7] Ping Hong. Interpretation of Requirements of Undergraduate Translation Teaching, Chinese Translators Journal, 2014(1):53-38.

[8] Chai Mingying. Zhang Ailing. Professional Translation Education Brought by Professionalization of Translation-- Thoughts Drawn from "The 3rd U.N. Momorandum of Understanding Signed on the Annual Meeting of Colleges and Universities”, East Journal of Translation, 2013(4):4-8.

[9] Zhong Weihe. Cultivation of Professional Translation Talents: Concept and Principle, East Journal of Translation, 2010(1):10-14.

[10]Zhuang Zhixiang. Construction of Chinese Translation Major--Problems and Countermeasures, Shanghai: Shanghai International Studies University, 2007.

[11] Zhu Ailing. Reform of Translation Teaching of Undergraduate English Major and Cultivation of Practical Translation Talents, Qingdao: Qingdao University of Science and Technology, 2010. 